\title{
Enhanced expression of type I interferon and toll-like receptor-3 in primary biliary cirrhosis
}

\author{
Yasushi Takii $^{1,3}$, Minoru Nakamura ${ }^{1,2}$, Masahiro Ito ${ }^{1,2}$, Terufumi Yokoyama ${ }^{1}$, \\ Atsumasa Komori, ${ }^{1,2}$, Yuki Shimizu-Yoshida ${ }^{1}$, Rumiko Nakao ${ }^{1}$, Koichiro Kusumoto ${ }^{1,2}$, \\ Shinya Nagaoka ${ }^{1,2}$, Koji Yano ${ }^{1,2}$, Seigo Abiru ${ }^{1,2}$, Toshihito Ueki ${ }^{1,2}$, Takehiro Matsumoto ${ }^{1,2}$, \\ Manabu Daikoku ${ }^{1,2}$, Ken Taniguchi ${ }^{1,2}$, Hikaru Fujioka ${ }^{1,2}$, Kiyoshi Migita ${ }^{1,2}$, Hiroshi \\ Yatsuhashi $^{1,2}$, Masahiro Nakashima ${ }^{4}$, Mine Harada ${ }^{3}$ and Hiromi Ishibashi ${ }^{1,2}$ \\ ${ }^{1}$ Clinical Research Center, National Hospital Organization (NHO) Nagasaki Medical Center, Nagasaki, Japan; \\ ${ }^{2}$ Department of Hepatology, Nagasaki University Graduate School of Biomedical Sciences, Nagasaki, Japan; \\ ${ }^{3}$ Department of Medicine and Biosystemic Science, Kyushu University Graduate School of Medical Sciences, \\ Fukuoka, Japan and ${ }^{4}$ Tissue and Histopathology Section, Division of Scientific Data Registry, Atomic Bomb \\ Disease Institute, Nagasaki University Graduate School of Biomedical Sciences, Nagasaki, Japan
}

\begin{abstract}
The pathogenesis of primary biliary cirrhosis (PBC) remains enigmatic. In order to address this issue, we analyzed by laser capture microdissection and real-time reverse transcription-polymerase chain reaction the site-specific expression of messenger RNA (mRNA) for cytokines (interferon (IFN)- $\alpha,-\beta,-\gamma$, interleukin (IL)-1 $\beta,-4$, $-6,-10,-12 p 40,-18$, tumor necrosis factor- $\alpha$ ) and toll-like receptors (TLRs) (TLR-2, $-3,-4,-7,-9$ ) in portal tract and liver parenchyma from patients with early-stage PBC. Expression of IFN- $\alpha,-\beta$ and TLR-3 proteins was also studied by immunohistochemistry. Autoimmune hepatitis (AIH) and chronic hepatitis C (CHC) served as disease controls. The expression levels of type I IFN (IFN- $\alpha,-\beta)$ and TLR-3 mRNAs, which are known to induce type I IFN, were significantly higher in portal tract and liver parenchyma as compared to AlH and CHC. A strong positive correlation between the mRNA levels of type I IFN and TLR-3 was also seen in both areas. Immunohistologically, IFN- $\alpha$ is present in the mononuclear cells in portal tract and sinusoidal cells. Macrophages in portal tract and hepatocytes expressed IFN- $\beta$ and TLR-3. Furthermore, the level of IFN- $\alpha$ mRNA in the portal tract was positively correlated with serum alkaline phosphatase. In conclusion, these data indicate that TLR-3 and type I IFN signaling pathways are active in both the portal tract and liver parenchyma of early-stage PBC, and form the basis for our hypothesis that these signaling pathways are involved in the pathophysiology of PBC.

Laboratory Investigation (2005) 85, 908-920. doi:10.1038/labinvest.3700285; Published online 25 April 2005
\end{abstract}

Keywords: cytokines; interferon- $\alpha$; interferon- $\beta$; laser capture microdissection; liver; toll-like receptors

Primary biliary cirrhosis (PBC) is a chronic cholestatic liver disease characterized by the destruction of intrahepatic bile ducts by autoimmune mechanisms. Since cytokines are pivotal factors regulating the inflammatory responses prevalent in many autoimmune disorders, the roles of cytokines have been previously investigated in the pathogenesis of PBC. ${ }^{1-7}$ Despite these inquiries, the significance of each cytokine in the microenvironment of the liver remains elusive. Furthermore, several reports sug-

Correspondence: Dr M Nakamura, MD, PhD, Clinical Research Center, National Hospital Organization (NHO) Nagasaki Medical Center and Department of Hepatology, Nagasaki University Graduate School of Biomedical Sciences, Kubara 2-1001-1, Omura, Nagasaki 856-8562, Japan.

E-mail: nakamuram@nmc.hosp.go.jp

Received 5 January 2005; revised and accepted 15 March 2005; published online 25 April 2005 gest that infectious agents may also be involved in the pathogenesis of PBC. ${ }^{8-13}$

Toll-like receptors (TLRs) play a crucial role in various inflammatory diseases. Among the 10 members of the TLR family reported in humans, each receptor recognizes different pathogens. ${ }^{14,15}$ TLRs act not only on innate immunity, but also on adaptive immunity via maturation of dendritic cells (DCs), and induction of a Th1 cell response. ${ }^{14}$ Furthermore, various cell types outside those directly involved in immune responses, including vascular endothelial cells, adipocytes, cardiac myocytes and intestinal epithelial cells, also are known to express TLRs to varying degrees. ${ }^{14}$ However, the role of TLRs in the pathogenesis of PBC has not been previously reported.

In addition to TLRs, type I interferon (IFN) also plays an important role in both innate and adaptive immunity. ${ }^{16,17}$ Type I IFN induces maturation of DCs 
to enhance antigen presentation, ${ }^{18}$ acts on $\mathrm{T}$ cells to drive Th1 cell differentiation, activates B cells and induces antibody production, ${ }^{19,20}$ and maintains survival of memory CD8 ${ }^{+}$T cells. $^{21}$ Type I IFN is induced by stimulation of TLR-3, $-4,-7$ and $-9,{ }^{14}$ and type I IFN plays an important role in the pathogenesis of autoimmunity, especially in systemic lupus erythematosus and rheumatoid arthritis. ${ }^{22-24}$

In this study, we analyzed the pathophysiology of PBC by investigating the expression levels of messenger RNAs (mRNA) encoding various cytokines and TLRs using quantitative real-time reversetranscription polymerase chain reaction (RT-PCR). Laser capture microdissection (LCM) enabled us to collect tissue samples from distinct areas of the liver, specifically portal tract and liver parenchyma. Our results clearly demonstrate that steady-state mRNA levels for IFN- $\alpha,-\beta$ and TLRs, particularly TLR-3, were upregulated in both the portal tract and liver parenchyma of PBC. Furthermore, we observed a strong positive correlation between steady-state levels of mRNAs for type I IFN (IFN- $\alpha,-\beta)$ and TLR3. These data are the first to demonstrate the activation of TLRs-type I IFN signaling specifically in PBC-diseased liver samples, and strongly suggest a role for these cytokines in the pathophysiology of early-stage (stage 1, 2) PBC.

\section{Materials and methods}

\section{Clinical Specimens}

Specimens of liver tissue collected by needle biopsy from nine patients with early stage (stage 1,2) of PBC and seven disease controls, including four autoimmune hepatitis (AIH) who were not under prednisolone treatment and three chronic hepatitis C (CHC) who were not under IFN therapy, were examined (Table 1). Written informed consent was obtained from each patient and the study protocol conformed to the ethical guidelines of the 1975 Declaration of Helsinki and was approved by the local ethics committee. The diagnosis of PBC was made on the basis of clinical and biochemical features, and diagnostic or compatible histological changes seen upon liver biopsy. $^{25}$ In all PBC patients, antimitochondrial antibodies (AMA) were detected by indirect immunofluorescence. AIH was diagnosed according to the criteria established for this disease, ${ }^{26,27}$ and CHC was diagnosed by positive serum hepatitis $\mathrm{C}$ virus-RNA with sustained liver injury. Each liver biopsy specimen was divided into two parts: The first part (more than $20 \mathrm{~mm}$ ) was directly fixed in 10\% formaldehyde and embedded in paraffin wax for histological diagnosis and immunohistochemistry. The second part (approximately 5-10 mm) was embedded in Tissue-Tek OCT compound (Sakura Finetek USA, Torrance, CA, USA), immediately frozen in liquid nitrogen and stored at $-80^{\circ} \mathrm{C}$ until use. Histological features of the paraffin sections were graded by two observers
(MI and YT) as follows: fibrosis, 0-4 (0, absent; 1, portal fibrosis; 2, bridging fibrosis; 3, bridging fibrosis with lobular distortion; 4, cirrhosis), and activity, 0-3 (0, none to minimal; 1, mild; 2, moderate; 3, severe). PBC specimens were also evaluated by Scheuer's classification: ${ }^{28}$ stage 1, florid duct lesion; stage 2, destruction of limiting plate with piecemeal necrosis or ductular proliferlation; stage 3 , presence of fibrous septa which is called scarring; stage 4 , cirrhosis.

\section{Tissue Preparation}

Under RNase-free conditions, $8 \mu \mathrm{m}$ frozen sections were cut with a cryostat (CM 1900, Leica, Germany) at $-20^{\circ} \mathrm{C}$ using a clean disposable blade for each tissue block. The sections were mounted on RNasefree uncoated glass slides (Arcturus Engineering, Mountain View, CA, USA) and were immediately fixed in $75 \%$ ethanol for $30 \mathrm{~s}$, and washed with RNase-free water for $30 \mathrm{~s}$. The specimens were stained with Mayer's hematoxylin including $1 \mathrm{U} / \mu \mathrm{l}$ of RNase inhibitor (Takara, Shiga, Japan) for $30 \mathrm{~s}$, rinsed in RNase-free water for $30 \mathrm{~s}$, stained with $25 \%$ pure eosin diluted with 95\% ethanol (including $1 \mathrm{U} / \mu \mathrm{l}$ of RNase inhibitor) for $20 \mathrm{~s}$. Dehydration was completed by rinsing the slides for $30 \mathrm{~s}$, once in $75 \%$ ethanol, $95 \%$ ethanol, twice in $100 \%$ ethanol, and for $3 \mathrm{~min}$ twice in xylene. The slides were air dried for $5 \mathrm{~min}$, a Prepstrip (Arcturus) was placed on the slide to flatten the tissue and remove nonadhering cellular fragments prior to LCM, and the slide was immediately used for LCM.

\section{Sampling of Portal Tract and Liver Parenchyma by LCM}

LCM was performed using AutoPix (Arcturus). Portal tract and liver parenchyma on the section was separately captured onto CapSure HS LCM Caps (Arcturus) (Figure 1). The nine serial sections of the same portal tract and liver parenchyma were captured by LCM. Histological features of the captured portal tract were graded as follows (Table 1): portal and periportal inflammation, 0-3 (0, normal; 1, mild: cell infiltration in less than $1 / 3$ of the portal tract; 2 , moderate: cell infiltration in $1 / 3$ to $2 / 3$ of the portal tract; 3 , severe: cell infiltration more than $2 / 3$ of the portal tract); piecemeal necrosis, $0-3$ (0, absent; 1 , mild: destruction for less than $1 / 3$ girth of limiting plate; 2 , moderate: destruction for $1 / 3$ to $2 / 3$ girth of limiting plate; 3 , severe: more than $2 / 3$ girth of limiting plate was destructed).

The number of bile ducts, the presence of chronic nonsupprative cholangitis (CNSDC) and the degree of bile duct proliferation were also evaluated in each captured portal tract (Table 1). To evaluate these variables, immunohistochemical staining for cytokeratin 19 (DAKO Japan, Kyoto, Japan) was performed by a standardized two-step method with 
Table 1 Profile of patients and histological features of portal tract which was captured by LCM

\begin{tabular}{|c|c|c|c|c|c|c|c|c|c|c|c|}
\hline $\begin{array}{l}\text { Case } \\
\text { no. }\end{array}$ & Age & Sex & Fibrosis & Activity & $\begin{array}{l}\text { Scheuer's } \\
\text { stage }\end{array}$ & Portal no & $\begin{array}{c}\text { Portal } \\
\text { inflammation }^{\mathrm{a}}\end{array}$ & $\begin{array}{l}\text { Piecemeal } \\
\text { necrosis }^{\mathrm{b}}\end{array}$ & $\begin{array}{l}\text { Number of } \\
\text { bile ducts }\end{array}$ & $C N S D C$ & $\begin{array}{c}\text { Bile duct } \\
\text { proliferation }^{\mathrm{c}}\end{array}$ \\
\hline \multicolumn{12}{|l|}{ PBC } \\
\hline 1 & 47 & M & 1 & 1 & 1 & 1 & 2 & 0 & 2 & + & 0 \\
\hline \multirow[t]{2}{*}{2} & 52 & $\mathrm{~F}$ & 2 & 1 & 2 & 2 & 1 & 1 & 0 & - & 0 \\
\hline & & & & & & 3 & 2 & 1 & 1 & + & 0 \\
\hline \multirow[t]{2}{*}{3} & 66 & $\mathrm{~F}$ & 1 & 1 & 1 & 4 & 3 & 2 & 0 & - & 0 \\
\hline & & & & & & 5 & 2 & 3 & 1 & + & 1 \\
\hline \multirow[t]{4}{*}{4} & 48 & $\mathrm{~F}$ & 1 & 2 & 2 & 6 & 2 & 0 & 1 & + & 0 \\
\hline & & & & & & 7 & 2 & 0 & 1 & - & 0 \\
\hline & & & & & & 8 & 2 & 1 & 0 & - & 0 \\
\hline & & & & & & 9 & 2 & 2 & 2 & + & 1 \\
\hline \multirow[t]{2}{*}{5} & 71 & $\mathrm{~F}$ & 1 & 1 & 2 & 10 & 2 & 2 & 1 & + & 2 \\
\hline & & & & & & 11 & 2 & 1 & 0 & - & 0 \\
\hline 6 & 54 & $\mathrm{~F}$ & 1 & 1 & 1 & 12 & 1 & 1 & 0 & - & 0 \\
\hline \multirow[t]{2}{*}{7} & 56 & $\mathrm{~F}$ & 2 & 1 & 2 & 13 & 2 & 1 & 2 & + & 0 \\
\hline & & & & & & 14 & 2 & 1 & 2 & - & 1 \\
\hline \multirow[t]{2}{*}{8} & 64 & $\mathrm{~F}$ & 2 & 2 & 2 & 15 & 3 & 3 & 0 & - & 2 \\
\hline & & & & & & 16 & 3 & 2 & 2 & + & 3 \\
\hline \multirow[t]{2}{*}{9} & 65 & $\mathrm{~F}$ & 1 & 1 & 1 & 17 & 1 & 0 & 1 & - & 0 \\
\hline & & & & & & 18 & 1 & 1 & 1 & - & 1 \\
\hline \multicolumn{12}{|l|}{$\mathrm{AIH}$} \\
\hline \multirow[t]{2}{*}{10} & 63 & $\mathrm{~F}$ & 3 & 3 & & 19 & 3 & 3 & 3 & & 3 \\
\hline & & & & & & 20 & 1 & 2 & 3 & & 3 \\
\hline \multirow[t]{2}{*}{11} & 74 & $\mathrm{~F}$ & 4 & 3 & & 21 & 2 & 2 & 0 & & 0 \\
\hline & & & & & & 22 & 3 & 3 & 1 & & 2 \\
\hline \multirow[t]{4}{*}{12} & 56 & $\mathrm{~F}$ & 2 & 2 & & 23 & 2 & 2 & 1 & & 1 \\
\hline & & & & & & 24 & 2 & 3 & 1 & & 2 \\
\hline & & & & & & 25 & 2 & 2 & 3 & & 2 \\
\hline & & & & & & 26 & 2 & 2 & 1 & & 0 \\
\hline \multirow[t]{4}{*}{13} & 46 & $\mathrm{~F}$ & 2 & 3 & & 27 & 3 & 3 & 1 & & 2 \\
\hline & & & & & & 28 & 2 & 3 & 1 & & 2 \\
\hline & & & & & & 29 & 3 & 3 & 2 & & 2 \\
\hline & & & & & & 30 & 3 & 3 & 1 & & 2 \\
\hline \multicolumn{12}{|l|}{$\mathrm{CHC}$} \\
\hline \multirow[t]{2}{*}{14} & 60 & $\mathrm{~F}$ & 1 & 1 & & 31 & 2 & 1 & 2 & & 0 \\
\hline & & & & & & 32 & 3 & 1 & 1 & & 2 \\
\hline 15 & 42 & $\mathrm{M}$ & 1 & 1 & & 33 & 2 & 0 & 2 & & 0 \\
\hline \multirow[t]{3}{*}{16} & 64 & $\mathrm{M}$ & 1 & 2 & & 34 & 2 & 2 & 1 & & 0 \\
\hline & & & & & & 35 & 2 & 1 & 1 & & 0 \\
\hline & & & & & & 36 & 1 & 1 & 1 & & 0 \\
\hline
\end{tabular}

CNSDC, chronic nonsuppurative destructive cholangitis.

Each portal tract which was captured by LCM was evaluated for the degree of portal inflammation ${ }^{\mathrm{a}}$, piecemeal necrosis ${ }^{\mathrm{b}}$ and bile duct proliferation $^{\mathrm{c}}$ as follows.

${ }^{\mathrm{a}} 0$, normal; 1 , mild; 2 , moderate; 3 , severe.

$\mathrm{b}_{0}$, none; 1 , mild; 2 , moderate; 3 , severe.

${ }^{\mathrm{c}} 0$, none; 1 , mild; 2 , moderate; 3 , severe.

ENVISION + (DAKO) using the same frozen sections used for LCM. The bile duct proliferation was graded 0-3: 0, absent; 1 , mild; 2 , moderate; 3 , severe.

\section{RNA Purification and Reverse Transcription}

Total RNA was extracted from each LCM sample and the RNA samples extracted from the same area were pooled and purified to a final volume of $11 \mu \mathrm{l}$ using the PicoPure RNA Isolation Kit (Arcturus). Singlestranded complementary DNA (cDNA) synthesis from $8 \mu \mathrm{l}$ of total RNA was performed using the SuperScript First-Strand Synthesis System (Invitrogen, Carlsbad, CA, USA) and a final volume of $20 \mu \mathrm{l}$, cDNA was stored at $-20^{\circ} \mathrm{C}$ until use.

\section{Real-Time PCR and Comparative Quantitation Analysis}

Steady-state mRNA levels were measured by realtime quantitative RT-PCR using the Light Cycler system (Roche Diagnostics, Mannheim, Germany) with LightCycler-DNA master SYBRGreen I (Roche Diagnostics). Each PCR reaction mixture contained $10 \mu \mathrm{l}$ of a 10 -fold dilution of cDNA template in water, $2 \mu \mathrm{l}$ of SYBRGreen I, $2 \mu \mathrm{l}$ of LightCyclerPrimer Set and $6 \mu \mathrm{l}$ of water in a total volume of $20 \mu \mathrm{l}$. After an initial denaturation at $95^{\circ} \mathrm{C}$ for $10 \mathrm{~min}$, PCR was performed for 45 cycles $\left(95^{\circ} \mathrm{C}\right.$ for $10 \mathrm{~s}, 68^{\circ} \mathrm{C}$ for $10 \mathrm{~s}, 72^{\circ} \mathrm{C}$ for $16 \mathrm{~s}$ ). Both a melting curve analysis and gel migration analysis were 

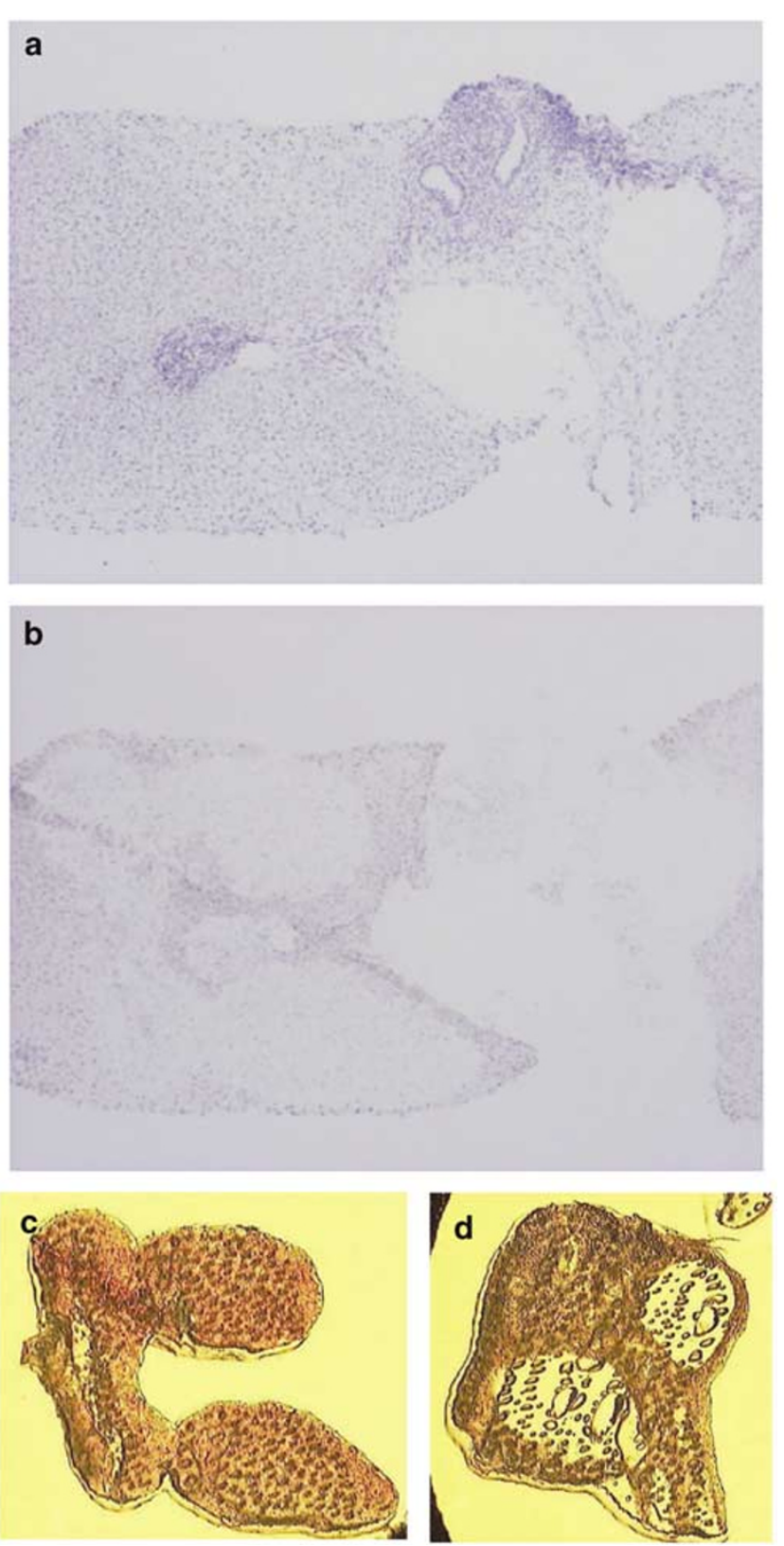

Figure $1 \mathrm{LCM}$ procedure for isolation of portal tract and liver parenchyma in case 1. (a) Before the LCM procedure, chronic nonsuppurative destructive cholangitis with infiltration of inflammatory cells is observed in the portal tract. (b) After the LCM procedure, the portal tract and liver parenchyma were separately captured. (c) Captured liver parenchyma on the membrane. (d) Captured portal tract (Portal No. 1) on the membrane (hematoxylin- and eosin-stained section, original magnification $\times 40$ ).

included in the experiments to verify the absence of nonspecific products such as primer-dimers. The LightCycler-primer set for GAPDH, IFN- $\alpha,-\beta,-\gamma$, interleukin (IL)-1 $\beta,-4,-6,-10,-12 \mathrm{p} 40,-18$, tumor necrosis factor- $\alpha$ (TNF- $\alpha$ ), TLR-2, $-3,-4,-7$ and -9 were purchased from Roche Diagnostics. Results are expressed as the ratio of each cytokine cDNA concentration relative to the concentration of GAPDH cDNA in the same sample. The cDNA concentration of GAPDH, a 'housekeeping' gene with relatively constant mRNA expression levels, was used to normalize samples for the amount of total cDNA amplified in each PCR reaction.

\section{Immunohistochemistry}

For immunohistochemical analysis of IFN $-\alpha,-\beta$ and TLR-3, formalin-fixed paraffin-embedded tissue blocks of PBC were cut into $4-\mu \mathrm{m}$ thick sections. The sections were deparaffinized in xylene and subsequently rehydrated in sequential ethanols (100-70\%). After washing three times with $10 \mathrm{mM}$ phosphate-buffered saline (PBS) ( $\mathrm{pH} 7.4)$, antigen retrieval was performed as follows: IFN- $\alpha$, heated at $121^{\circ} \mathrm{C}$ by autoclave for $15 \mathrm{~min}$; IFN- $\beta$ and TLR-3, heated by microwave at $95^{\circ} \mathrm{C}$ for $15 \mathrm{~min}$, then washed twice in PBS for $5 \mathrm{~min}$. The sections were treated with peroxidase blocking solution (DAKO Japan, Kyoto, Japan) for $5 \mathrm{~min}$, and incubated with each primary antibody for $60 \mathrm{~min}$ at room temperature. The primary antibodies used were a 1:50 dilution of anti-IFN- $\alpha$ rabbit polyclonal antibody (Santa Cruz Biotechnology, Santa Cruz, CA, USA), a 1:100 dilution of anti-IFN- $\beta$ mouse monoclonal antibody (PBL Biomedical Laboratories, Piscataway, NJ, USA) and a 1:50 dilution of anti-TLR-3 goat polyclonal antibody (Santa Cruz Biotechnology). A standardized two-step method with ENVISION + (DAKO) was used for IFN- $\alpha$ and IFN- $\beta$ antibody detection, whereas detection of TLR-3 antibodies required formation of streptavidin-biotin-peroxidase complexes using the Histofine SAB-PO (G) kit for goat primary antibodies (Nichirei, Tokyo, Japan) and $10 \%$ normal rabbit serum for protein blocking. The reaction products were visualized using $3,3^{\prime}$ diaminobenzidine as a chromogen (DAKO), and counterstained with Mayer's hematoxylin (DAKO). Negative controls were prepared identically except for omission of all primary antibodies.

\section{Statistical Analysis}

Data were expressed as the mean \pm s.d. of the target cytokines or TLR mRNA concentration relative to the concentration of GAPDH mRNA in each sample. Mean values were compared using the Welch's $t$ test. Correlation significance was assessed using Pearson's correlation coefficient test and Spearman's rank test for nonparametric data. $P<0.05$ was considered significant. All statistical calculations were performed using Statcel2 (OMS, Saitama, Japan).

\section{Results}

\section{Expression of Cytokine mRNAs in the Portal Tract}

The numbers of portal tract samples captured from PBC-, AIH- and CHC-diseased liver specimens were 18, 12 and 6 , respectively (Table 1). The steady-state 
concentration of individual cytokine cDNAs prepared from each portal tract mRNA sample was measured relative to the concentration of GAPDH cDNA for the same sample (Figure 2a). In portal tracts, relative levels of IFN- $\alpha$ mRNA were significantly higher in PBC (mean \pm s.d.: $0.175 \pm 0.168$ ) than either AIH $(0.033 \pm 0.025, P<0.01)$ or $\mathrm{CHC}$ $(0.046 \pm 0.044, P<0.01)$. IFN- $\beta$ mRNA levels were significantly higher $(P<0.01)$ in PBC $(0.196 \pm 0.137)$ than in AIH $(0.067 \pm 0.050)$. The relative concentration of IFN- $\beta$ mRNA was also higher in PBC than in CHC $(0.077 \pm 0.044)$, but this difference did not achieve $P<0.05$ statistical significance. The relative level of IFN- $\gamma$ mRNA also was significantly higher in PBC than CHC $(0.034 \pm 0.041$ vs $0.004 \pm 0.021$, $P<0.05)$. Statistical analyses of the remaining real-time PCR measurements revealed no further significant differences between the relative concentrations of other cytokine mRNAs (IL-1 $\beta$, IL-4, IL-6, IL-10, IL-12p40, IL-18 and TNF- $\alpha$ ) in samples prepared from PBC-, AIH- and CHC-diseased tissue. (The results of IL-4, IL-12p40, IL-18 and TNF- $\alpha$ are not shown in Figure 2.)

\section{Expression of Cytokine mRNAs in the Liver Parenchyma}

One area of liver parenchyma was captured from each section by LCM. In order to avoid the influence of inflammatory cells, the captured liver parenchyma was intentionally avoided from contamination of focal necrosis, indicating that the mRNAs from liver parenchyma were primarily derived from hepatocytes and sinusoidal cells (Kupffer cells, sinusoidal endothelial cells, hepatic stellate cells). The number of parenchyma captured from the specimens of PBC-, AIH- and CHC-diseased livers were 9, 4 and 3, respectively. Type I IFN (IFN- $\alpha$, IFN- $\beta$ ) mRNAs were present in most of the liver parenchyma samples (Figure 2b), whereas mRNAs of other cytokines were not detected.

Although the quantities of IFN- $\alpha$ and IFN- $\beta$ mRNAs from liver parenchyma samples were two to five times less than portal tract samples, the expression patterns of these mRNAs between PBC-, AIH- and CHC-diseased livers were similar to portal tract samples. In PBC parenchyma samples, the a
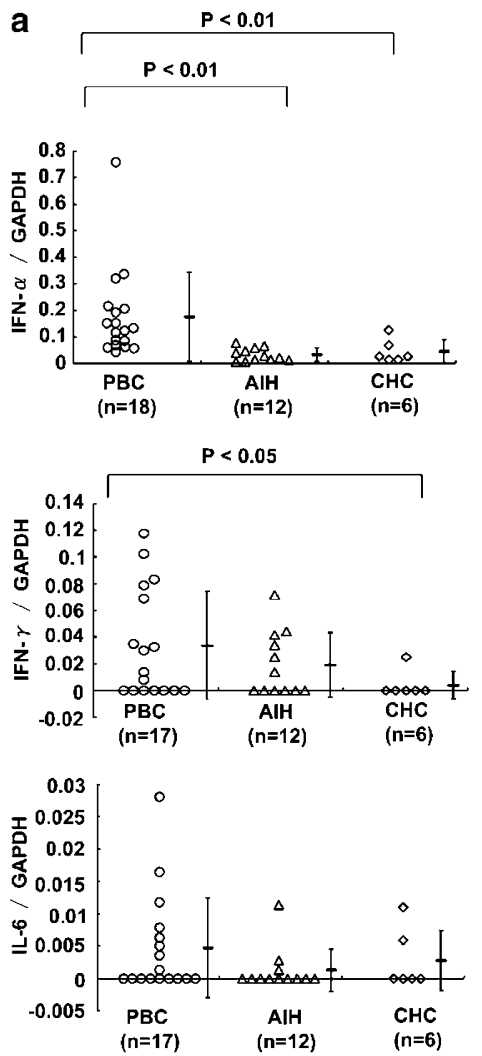
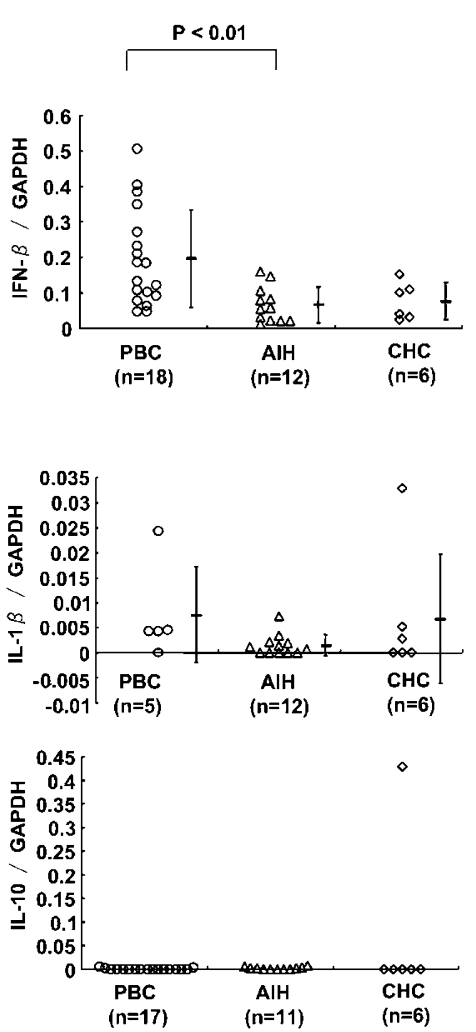

b

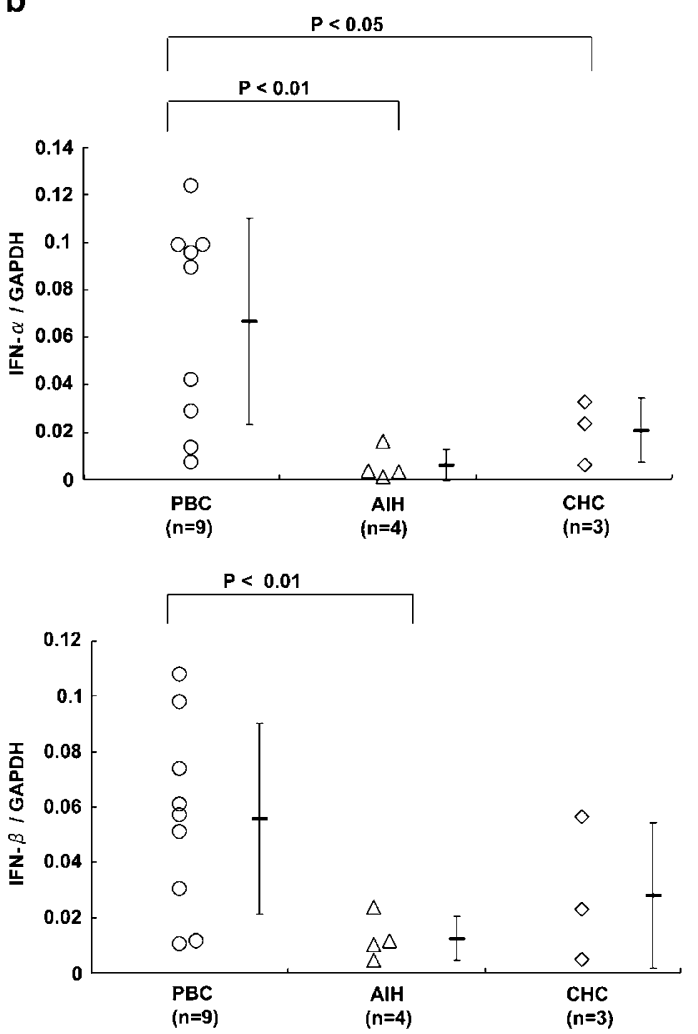

Figure 2 Comparision of gene expression in the portal tract and liver parenchyma from PBC-, AIH- and CHC-diseased liver specimens by RT-PCR. Steady-state levels of mRNAs for all target genes were normalized relative to GAPDH mRNA levels. (a) The expression of cytokine messages in portal tract. (b) Expression of cytokine mRNAs in liver parenchyma. (c) Expression of TLR mRNAs in portal tracts. (d) Expression of TLR mRNAs in liver parenchyma. IFN- $\alpha$ and $-\beta$ are the only cytokines detected in liver parenchyma. (a, b) IFN- $\alpha$ mRNA levels are significantly higher in PBC samples than in AIH or CHC samples from portal tract and liver parenchyma. IFN- $\beta$ mRNA levels are significantly higher in PBC than AIH samples in both portal tract and liver parenchyma. IFN- $\gamma$ mRNA levels are significantly higher in the portal tract of PBC specimens than in CHC. (c, d) TLR-3 mRNA levels in the portal tract are significantly higher in PBC than in AIH or CHC. TLR-9 mRNA levels in portal tracts from PBC samples are significantly higher than AIH samples' levels. In liver parenchyma, TLR3, -4 and -7 mRNAs are more abundant in PBC than AIH specimens. Mean values \pm s.d. are indicated by horizontal bars and statistical significance was calculated by the Welch's $t$-test. $(\bigcirc) \mathrm{PBC},(\triangle) \mathrm{AIH},(\diamond) \mathrm{CHC}$. 

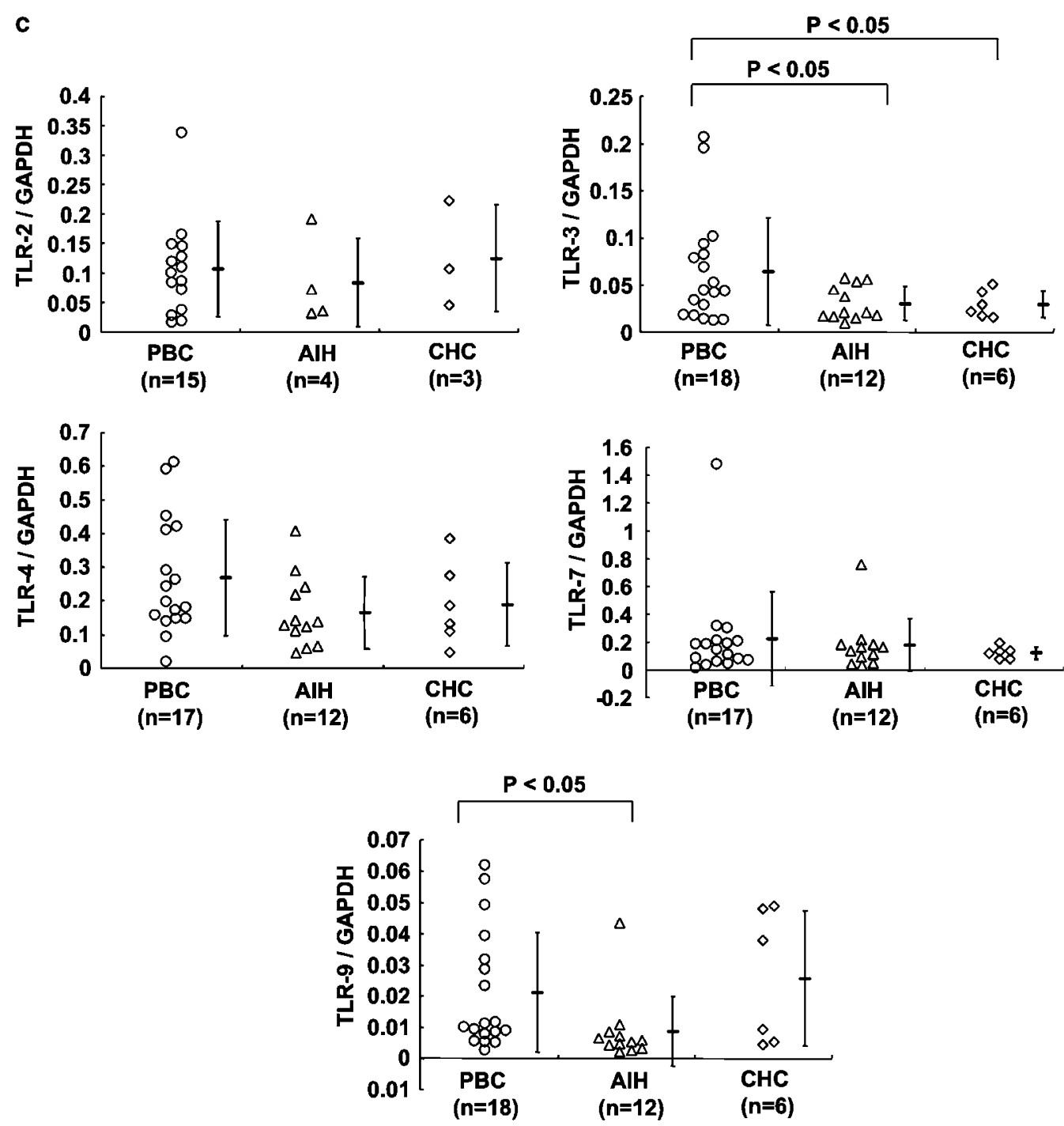

Figure 2 Continued.

relative amount of IFN- $\alpha$ mRNA $(0.066 \pm 0.043)$ was significantly higher than in AIH $(0.006 \pm 0.007$, $P<0.01)$ or CHC $(0.021 \pm 0.014, P<0.05)$ samples, and IFN- $\beta$ mRNA was significantly more abundant in PBC-diseased liver samples compared to AIH $(0.056 \pm 0.034$ vs $0.013 \pm 0.008, P<0.01)$. The mean values of IFN- $\alpha$ and IFN- $\beta$ mRNAs from parenchyma showed a positive correlation with portal tract abundance from the same patients: IFN- $\alpha$ (Spearman $r=0.69, n=16, P<0.01$ ), IFN- $\beta$ (Spearman $r=0.62$, $n=16, P<0.05)$ (data not shown).

\section{Expression of TLR mRNAs in the Liver}

Expression of TLR-2, -3, -4, -7, -9 mRNAs in portal tract (Figure 2c) and liver parenchyma (Figure 2d) were measured by real-time PCR from prepared cDNA samples. All TLR mRNAs were detected in both areas with the expression in portal tract two- to 18-fold higher than in liver parenchyma.
In the portal tract, TLR-3 mRNA levels were significantly higher in PBC $(0.064 \pm 0.057)$ relative to AIH $(0.031 \pm 0.018, P<0.05)$ or $\mathrm{CHC}(0.030 \pm$ $0.014, P<0.05)$ samples (Figure 2c). The expression of TLR-9 was also significantly higher in PBC compared to AIH $(0.021 \pm 0.019$ vs $0.009 \pm$ 0.011, $P<0.05$ ) samples (Figure 2c). In the liver parenchyma, TLR-3 mRNA abundance was significantly higher in PBC than in AIH samples (0.023 \pm 0.017 vs $0.004 \pm 0.002, P<0.05$ ) (Figure $2 \mathrm{~d}$ ), as are TLR-4 and TLR-7 mRNA levels $(0.130 \pm 0.082$ vs $0.032 \pm 0.015, \quad P<0.01 ; \quad 0.032 \pm 0.021$ vs $0.010 \pm$ $0.007, P<0.05$, respectively) (Figure 2d).

\section{Positive Correlation between mRNA of Type I IFN and TLR-3 in the Liver}

Steady-state levels of type I IFN and TLR-3 mRNAs from PBC samples were higher than in other liver diseases in both portal tract and liver parenchyma 

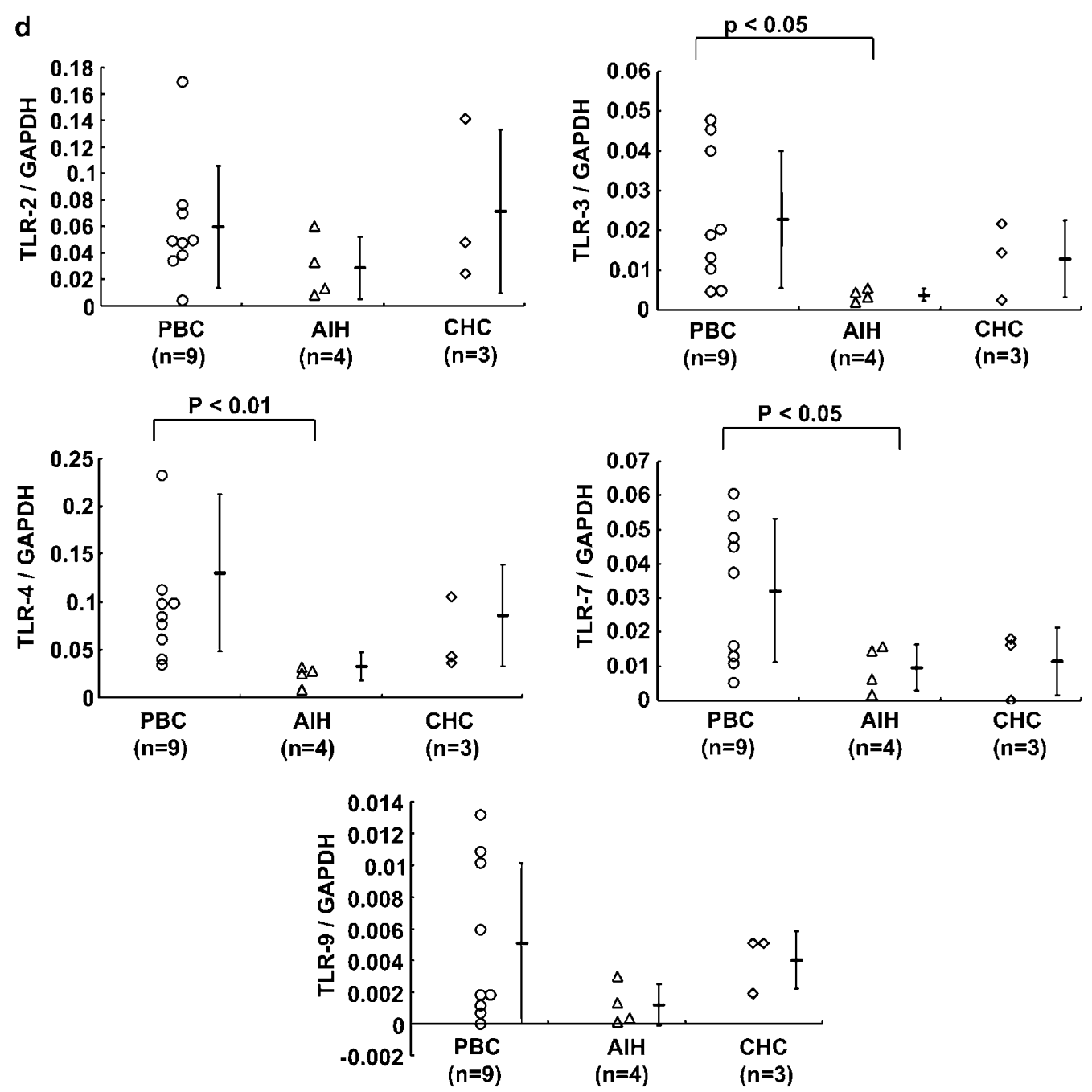

Figure 2 Continued.

(Figure 2a-d). We correlated the relative abundance of type I IFN to TLR mRNAs in portal tract and found a significant positive correlation between IFN- $\alpha$ and TLR-3 (Figure 3a) $(r=0.87, n=36, P<0.0001)$ and between IFN- $\beta$ and TLR-3 (Figure $3 b)(r=0.78$, $n=36, P<0.0001)$. In the liver parenchyma, there was also a significant positive correlation between the relative abundance of IFN- $\alpha$ and IFN- $\beta$ mRNAs with TLR-3 (Figure 3c,d) (IFN- $\alpha$ : $r=0.86, n=16$, $P<0.0001$; IFN- $\beta: r=0.86, n=16, P<0.0001$ ).

\section{Localization of TLR-3, IFN- $\alpha$ and IFN- $\beta$ in PBC-Diseased Liver Biopsies}

To identify the location of IFN- $\alpha$, IFN- $\beta$ and TLR-3 proteins in PBC-diseased liver, immunohistochemical analysis was performed on nine paraffinembedded samples of tissue derived from the same PBC patient's biopsies used for LCM. IFN- $\alpha$ was detected in a number of mononuclear cells (including lymphocytes and plasma cells) and some injured biliary epithelial cells in florid duct lesions of the
PBC samples (Figure 4a). Macrophages in portal tract were frequently positive for IFN- $\alpha$ (Figure $4 \mathrm{~b}$ ). In liver parenchyma, IFN- $\alpha$ was mainly detected in Kupffer cells (Figure 4c), and not in hepatocytes. Occasionally, some vessels in portal tract and in periportal area showed IFN- $\alpha$ expression (Figure $4 d)$. IFN- $\beta$ was detected in macrophages of the portal tract (Figure 4e). In contrast to IFN- $\alpha$, the expression of IFN- $\beta$ in PBC-diseased liver parenchyma was restricted to a diffuse cytoplasmic staining pattern in hepatocytes, whereas sinusoidal cells showed no expression (Figure 4f). TLR-3 was expressed in portal tract macrophages (Figure 5a), and infrequently in plasma cells (Figure 5b). As with IFN- $\beta$, TLR-3 was only detected in hepatocytes from liver parenchyma (Figure 5c).

\section{Cytokines and TLRs were not Related to the Pathological Features of the Portal Tract}

Prior to LCM procedure, each portal tract was evaluated for pathological features, based on the 

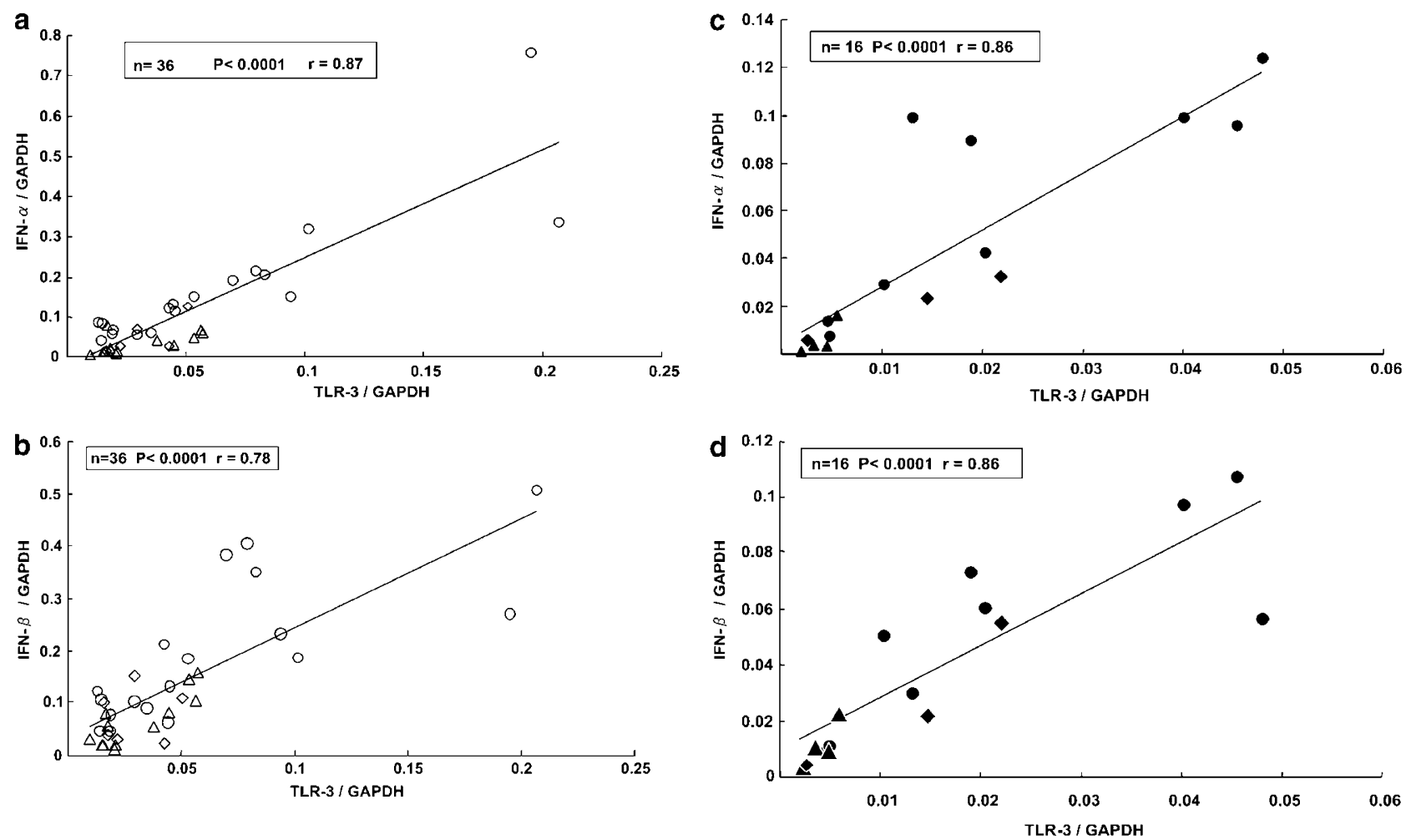

Figure 3 Correlation between the mRNA expression of TLRs and type I IFN in portal tract and liver parenchyma. There are strong positive correlations between TLR-3 and IFN- $\alpha(\mathbf{a}, \mathbf{c})$, TLR-3 and IFN- $\beta$ (b, d). ( $\bigcirc$ ) Portal tract of PBC, $(\bullet)$ liver parenchyma of PBC, $(\triangle)$ portal tract of $\mathrm{AIH},(\mathbf{\Delta})$ liver parenchyma of $\mathrm{AIH},(\diamond)$ portal tract of $\mathrm{CHC},(\diamond)$ liver parenchyma of CHC.

degree of portal inflammation, piecemeal necrosis, number of bile ducts, presence of CNSDC and the degree of bile duct proliferation as described in Materials and methods (Table 1). We then studied whether expression levels of cytokines or TLRs correlated with these pathological variables. There was no positive correlation between mRNAs of cytokines or TLRs and any pathological variables in the captured portal taracts.

\section{Correlation Between Type I IFN in the Liver and Clinical Parameters}

To investigate the role of localized type I IFN production on the PBC pathophysiology, we looked for significant correlations between steady-state levels of type I IFN or TLR-3 mRNA in the liver and clinical parameters in the sera at the time of liver biopsy. These included alanine aminotransferase (ALT), alkaline phosphatase (ALP), AMA and IgM (Table 2). When there were more than two portal tracts captured from the same biopsy specimen, the mean value of IFN- $\alpha,-\beta$ and TLR- 3 mRNA were calculated as a representative value for each specimen (Table 2). A significant positive correlation was only seen between IFN- $\alpha$ mRNA in the portal tract and ALP in the sera $(r=0.75, n=9, P<0.05)$ in PBC (Figure 6).

\section{Discussion}

We used LCM for isolating portal tract and liver parenchyma from frozen sections of liver needle biopsies. This technique pinpointed the target sites for specimen collection and allowed us to investigate the gene expression of cytokines and TLRs in each specific liver area. Although several studies have analyzed cytokine expression in liver of PBC patients, ${ }^{1-7}$ this is the first study to measure the steady-state expression levels of cytokines and TLRs in early stages of PBC within separate liver microenvironments of the portal tract and liver parenchyma.

Th1 cells are important for the pathogenesis of various autoimmune diseases, ${ }^{29}$ whereas Th2 cells contribute to allergic diseases. ${ }^{30}$ According to several previous reports, in the liver of PBC, Th1 was found to be dominant ${ }^{3-5,31}$ or present in combination with Th2. ${ }^{32}$ The cytokines IFN- $\gamma$ and IL-4, IL-6 or IL-10 are hallmarks of Th1 and Th2, respectively. Since our PCR analyses detected only low levels of IL-10 mRNA, and no IL-4 mRNA in PBC portal tract samples, we measured the relative abundance of IFN- $\gamma$ to IL-6 mRNA to infer the relative ratio of Th1 to Th2 balance. Quantitative PCR analyses demonstrated that Th1 cytokines predominated in PBC portal tract, although heterogeneity with Th2 cytokines was also present (data not shown). 

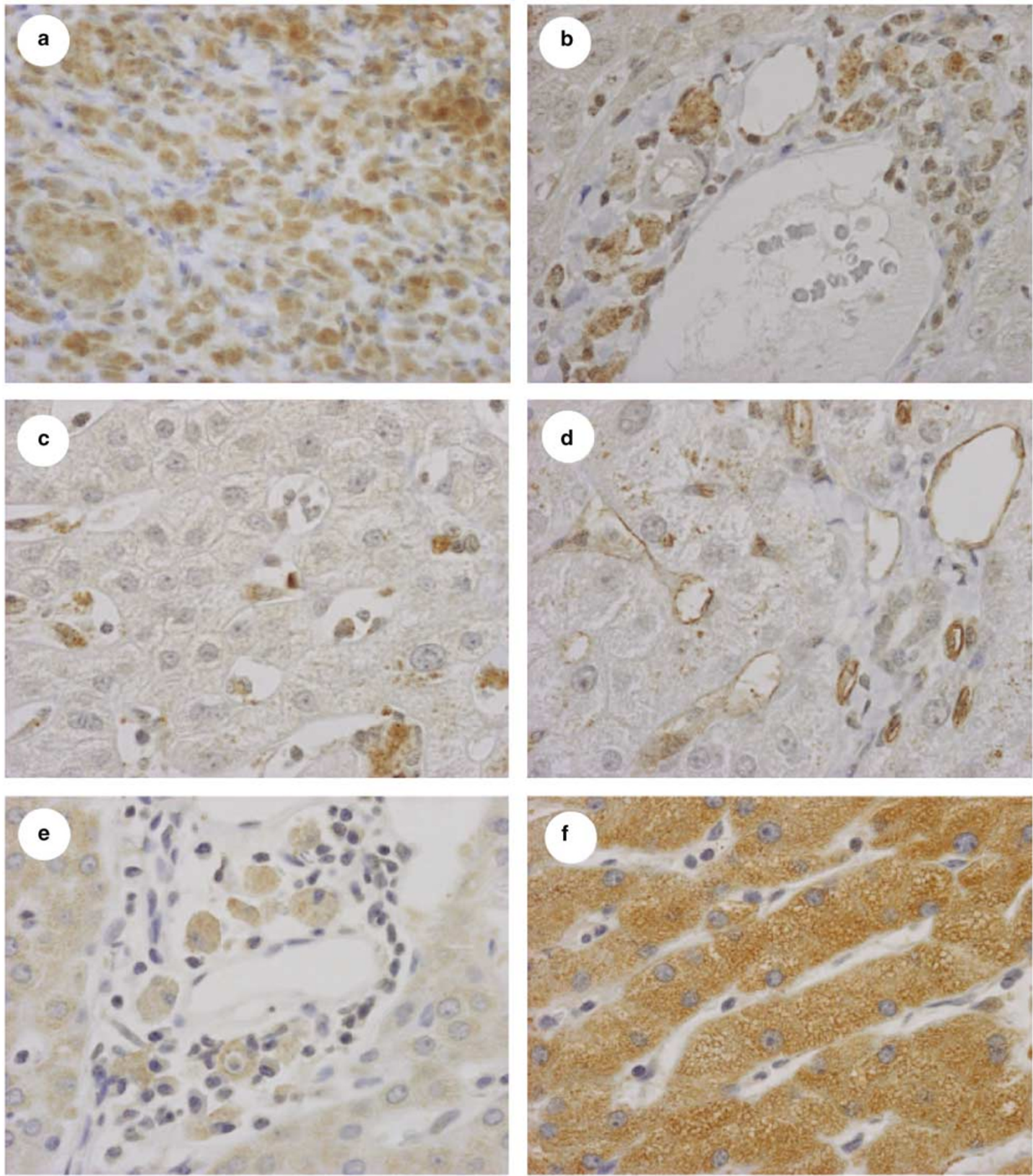

Figure 4 Immunohistochemistry of type I IFN in PBC-diseased liver. (a-d) Immunostaining for IFN- $\alpha$. (e-f) Immunostaining for IFN- $\beta$. (a) Mononuclear cells in portal tract are positive for IFN- $\alpha$. Bile ducts are also weakly positive. (b) Macrophages in portal tract are positive for IFN- $\alpha$. (c) Kupffer cells in the liver parenchyma, (d) vessels of the portal tract and periportal area are positive for IFN- $\alpha$. (e) Macrophages and (f) hepatocytes are positive for IFN- $\beta$. Kupffer cells are negative for IFN- $\beta$ (counterstained with hematoxylin, original magnification $\times 400)$.

While previous in situ hybridization experiments ${ }^{5}$ demonstrated localization of cytokine messages primarily in portal tract, the quantitative PCR analyses described here detected type I IFN (IFN- $\alpha$ and IFN- $\beta$ ) mRNAs not only in portal tract but also in most liver parenchyma (Figure 2b). Levels of IFN$\alpha$ were approximately 5 -fold higher in portal tract specimens from PBC patients than in those from 

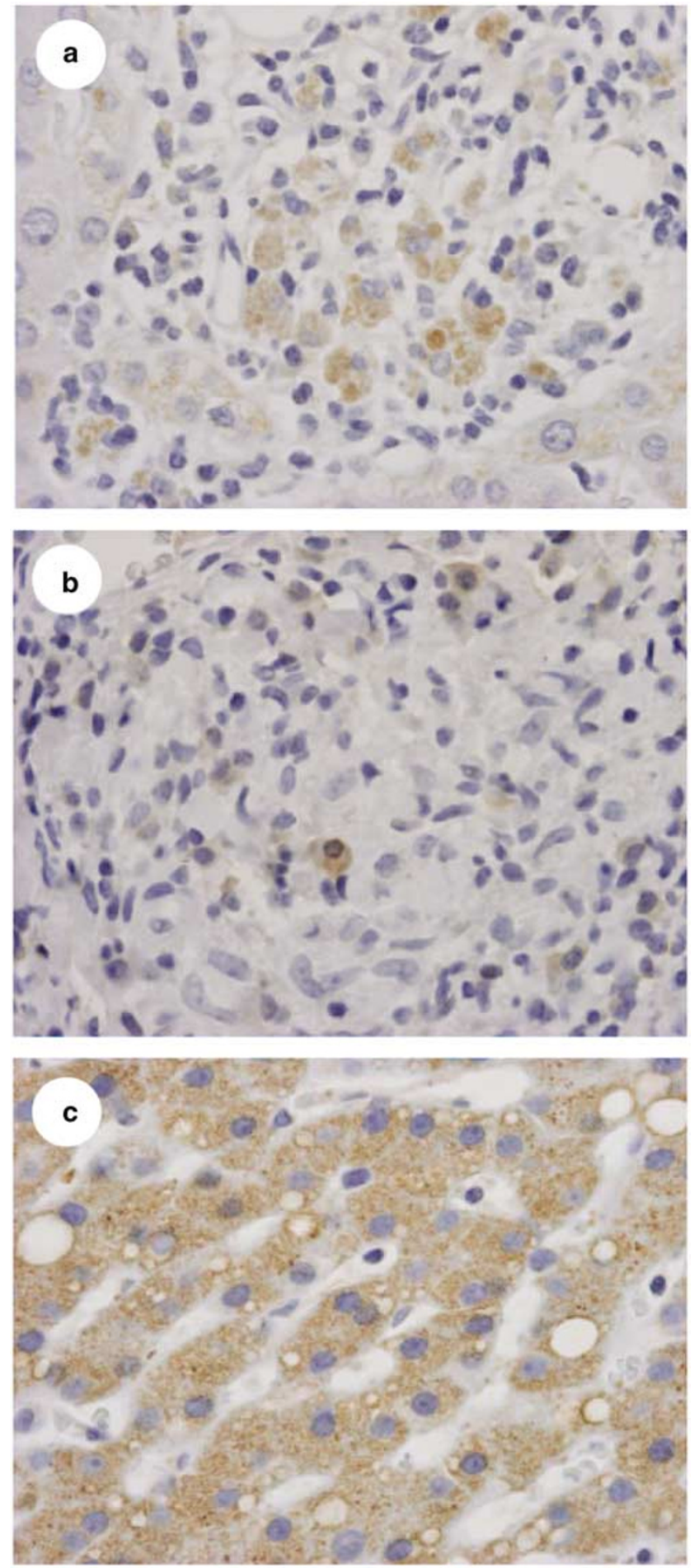

Figure 5 Immunohistochemistry of TLRs in PBC-diseased liver. (a-c) Immunostaining for TLR-3. (a) Macrophages and (b) some of the plasma cells in the portal tract are positive for TLR-3. (c) Hepatocytes are only positive cells in liver parenchyma (counterstained with hematoxylin, original magnification $\times 400$ )

either AIH or CHC patients, and 10-fold higher in PBC-diseased liver parenchyma than in AIH-diseased parenchyma. In PBC-diseased portal tract and parenchyma, the relative abundance of IFN- $\beta$ mRNA was three- to four-fold higher than in samples from AIH patients.

Since type I IFNs are cytokines induced by viral infection or double-stranded RNA (dsRNA), ${ }^{33,34}$ it is possible that as yet undefined viral or bacterial microbial agents may be involved in PBC pathogenesis. Several reports suggest a possible link between infectious agents and PBC. Shimoda et $a l^{8,9}$ reported 'molecular mimicry', in which $\mathrm{T}$ cells reactive to mitochondrial antigens such as the E2 component of pyruvate dehydrogenase complex crossreacted with enterobacterial antigens. In other reports, Escherichia coli urinary tract infection has been associated with PBC. ${ }^{10,11}$ Harada et $a l^{12}$ noted the presence of 16S ribosomal RNA from Propionibacterium acnes in PBC granuloma, and $\mathrm{Xu}$ et $a 1^{13}$ recently cloned the proviral genome from beta-retrovirus from the perihepatic lymph nodes of PBC patients. The sum of these results suggests the involvement of either bacterial or viral agents in the pathogenesis of PBC.

To investigate why type I IFN mRNAs are elevated in PBC, we examined the steady-state levels of TLR mRNAs in both portal tract and liver parenchyma. By recognizing structurally conserved bacterial and viral components, TLRs constitute the first step in innate immunity. ${ }^{14}$ TLRs also play an important role in the induction of acquired immunity by driving Th1 cell response. ${ }^{14}$ Recent evidence indicates that type I IFN is induced by the signaling of TLR-3 (a receptor for dsRNA and polyriboinosinic polyribocytidylic acid (poly I:C)), TLR-4 (a receptor for lipopolysaccharide (LPS)), TLR-7 (a receptor for single-stranded RNA) and TLR-9 (a receptor for CpG DNA) in macrophage and DCs. ${ }^{14,35-37}$ Our data indicate that steady-state levels of TLR-3 and TLR9 mRNAs are higher in the portal tract of PBC liver samples than in samples from AIH and CHC patients (Figure 2c), while TLR-3, -4 and -7 mRNA levels were higher in the PBC liver parenchyma than in $\mathrm{AIH}$ and CHC (Figure 2d). In both portal tract and liver parenchyma, there was a strong positive correlation between steady-state mRNA levels of TLR-3 and type I IFN (Figure 3). These results are consistent with the positive feedback observed in macrophages, DCs and monocytes in vitro, where stimulation of TLR3 by ligand activates type I IFN, which in turn induces the expression of TLR-3 mRNA. ${ }^{36,38-40}$

Our immunohistochemical analyses showed that TLR-3 and IFN- $\beta$ localize primarily to portal tract macrophages and hepatocytes, whereas IFN- $\alpha$ was detected primarily in inflammatory cells (plasma cells, lymphocytes, macrophages) in the portal tract and in Kupffer cells. These data are consistent with previous studies of IFN- $\alpha$ localization in liver biopsies from patients with viral hepatitis, ${ }^{41-46}$ in which Kupffer cells, lymphocytes and macrophages showed IFN- $\alpha$ positive staining. While hepatocytes have also been previously reported to express IFN$\alpha^{41,43-45}$ in chronic viral hepatitis, the expression of IFN- $\beta$ in hepatocytes has not been demonstrated by 
Table 2 Clinical data of PBC patients at the time of liver biopsy

\begin{tabular}{|c|c|c|c|c|c|c|c|}
\hline \multirow[t]{2}{*}{ Case no. } & \multirow[t]{2}{*}{$A L T(I U / I)$} & \multirow[t]{2}{*}{$A L P(I U / I)$} & \multirow[t]{2}{*}{$A M A$ (titer) } & \multirow[t]{2}{*}{$\operatorname{Ig} M(\mathrm{mg} / \mathrm{dl})$} & \multicolumn{3}{|c|}{ Mean value of target genes in portal tract } \\
\hline & & & & & $I F N \alpha^{\mathrm{a}}$ & $I F N \beta^{\mathrm{b}}$ & $T L R 3^{\mathrm{C}}$ \\
\hline 1 & 50 & 326 & 160 & 185 & 0.0432 & 0.0473 & 0.014 \\
\hline 2 & 30 & 253 & 160 & 174 & 0.0857 & 0.1152 & 0.0138 \\
\hline 3 & 18 & 383 & 320 & 220 & 0.1568 & 0.2982 & 0.0561 \\
\hline 4 & 173 & 2220 & 640 & 349 & 0.3556 & 0.2316 & 0.1051 \\
\hline 5 & 58 & 652 & 80 & 418 & 0.0584 & 0.0977 & 0.0322 \\
\hline 6 & 51 & 740 & 40 & 303 & 0.1522 & 0.1852 & 0.0531 \\
\hline 7 & 38 & 556 & 640 & 211 & 0.0638 & 0.0631 & 0.0189 \\
\hline 8 & 31 & 543 & 160 & 550 & 0.1786 & 0.2915 & 0.0884 \\
\hline 9 & 18 & 359 & 160 & 169 & 0.2265 & 0.3206 & 0.1261 \\
\hline
\end{tabular}

${ }^{\mathrm{a}}$ Mean value of the level of IFN- $\alpha$ mRNA in portal tracts in each patient.

${ }^{b}$ Mean value of the level of IFN- $\beta$ mRNA in portal tracts in each patient.

${ }^{\mathrm{C}}$ Mean value of the level of TLR3 mRNA in portal tracts in each patient.

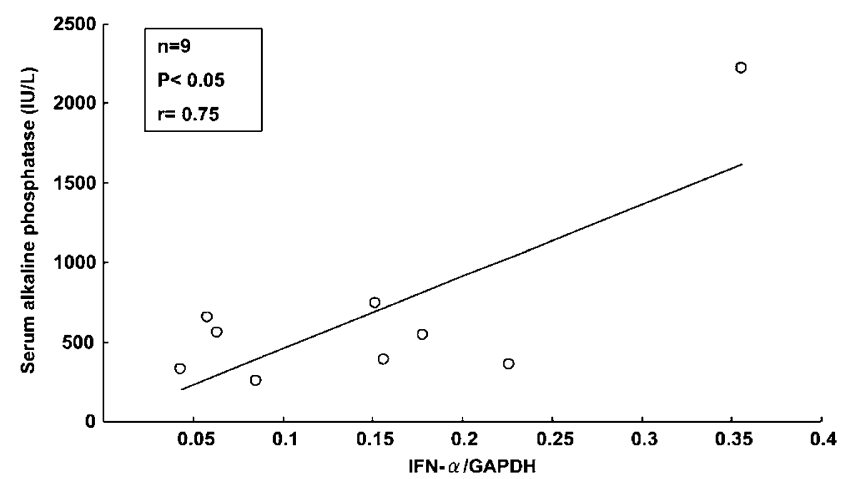

Figure 6 Correlation between the mRNA expression of IFN- $\alpha$ and serum ALP in PBC patients. There is positive correlation between IFN- $\alpha$ mRNA in the portal tract and serum ALP.

immunohistochemistry in vivo. Only a few report is available concerning the mRNA expression of IFN- $\beta$ in hepatocytes in vivo or hepatocyte cell lines in vitro. ${ }^{47,48}$ Therefore, the expression of IFN- $\beta$ in hepatocytes at a protein level is, to our knowledge, the first definite demonstration by immunohistochemistry. The role of IFN- $\beta$ signaling pathway via TLRs is now under investigation using primary human hepatocytes and ligands for TLRs including poly I:C and LPS.

Since we observed an overlap in the pattern of immunohistochemical staining for TLR-3 and IFN- $\beta$ in portal tract macrophages and in liver parenchyma hepatocytes, we hypothesize that the presumed stimulation of IFN- $\beta$ production by TLR-3 occurs in these cells. TLR- 3 stimulation of IFN- $\alpha$ production may depend on macrophages that express both TLR-3 and IFN- $\alpha$ in the portal tract, even though TLR-3 was not detected in many IFN- $\alpha$-producing cells (mononuclear cells). In the case of liver parenchyma, the highly positive correlation between TLR-3 and IFN- $\alpha$ appears to depend on TLR-3 expressed in hepatocytes and IFN- $\alpha$ expressed in sinusoidal cells. In this study, steady-state levels of TLR-4, -7 and -9 mRNA were higher in PBC than in other liver diseases, suggesting that, in addition to TLR-3, signaling via these TLRs may also contribute to the production of type I IFN. Numerous other reports also suggest coupling of TLR and type I IFN activities: TLR-4, TLR-7 and TLR-9 have been reported to induce steady-state mRNA and protein levels of type I IFNs, ${ }^{14,49,50}$ and type I IFNs have been reported to upregulate expression of TLR-7 and TLR-9 mRNAs. ${ }^{38}$

We also analyzed whether expression of cytokines and TLRs correlated with pathological features of portal tracts (Table 1). The pathological variables including portal inflammation, piecemeal necrosis, number of bile ducts, presence of CNSDC and bile duct proliferation did not correlate with either cytokines or TLRs mRNA. On the other hand, a significant correlation was observed between IFN- $\alpha$ mRNA in the portal tract and serum ALP, suggesting the importance of local production of type I IFN in the pathophysiology of PBC.

Other factors that could stimulate TLRs and thereby promote type I IFN production include exogenous TLR ligands, including dsRNA, LPS, single-stranded RNA and CpG DNA, which may flow into the liver via portal blood. In fact, in chronic liver diseases such as liver cirrhosis, the upregulation of TLR-2 in the peripheral mononuclear cells was reported. ${ }^{51}$ The liver injury mediated by TLR-4 on stellate cells was also reported. ${ }^{52}$ In these cases, TLRs signaling is considered to be a key molecule for progression of chronic liver disease, since abundant ligands for TLRs are absorbed from the gut and flow into the liver via portal blood. Endogenous factors derived from apoptotic or necrotic cells, such as genomic or mitochondrial DNA, have been shown to induce TLRs-type I IFN signaling and lead to autoimmunity in systemic lupus erythematosus and rheumatoid arthritis. ${ }^{19,24}$ Similarly, Kariko et $a l^{53}$ reported that stimulation of DCs by endogenous RNA from necrotic cells occurred via TLR-3 and resulted in the secretion of type I IFN in vitro. 
Thus, although the cause of sustained stimulation of TLR-type I IFN signaling pathways in PBC is currently unknown, our data indicate that the enhanced production of type I IFN via TLR signaling may play an important role in the sustained inflammation and autoimmunity that occurs during a dominant Th1 response, and that TLR-type I IFN signaling may be an important molecular target for future treatment of PBC.

\section{Acknowledgements}

This study was supported in part by Grants-in-Aid for Scientific Research from the Ministry of Health, Labour and Welfare of Japan, Grants-in-Aid for Scientific Research from Japan Society for the Promotion of Science and Grants-in-Aid for Scientific Research from the Ministry of Education, Culture, Sports, Science and Technology of Japan. We thank Dr Michitami Yano, CEO of Nagasaki Prefectural Hospitals, Nagasaki, Japan, Dr Michiaki Koga, National Hospital Organization (NHO) Ureshino Medical Center, Saga, Japan for helpful comments and encouragement, Miss Yuko Kataoka and Miss Mika Fukuda, Clinical Research Center, National Hospital Organization (NHO) Nagasaki Medical Center, Nagasaki, Japan, for excellent technical assistance. We also thank all the staff of the Division of Gastroenterology, National Hospital Organization (NHO) Nagasaki Medical Center, Nagasaki, Japan, who were involved in liver biopsy procedures and patients's care.

\section{References}

1 Lohr HF, Schlaak JF, Gerken G, et al. Phenotypical analysis and cytokine release of liver-infiltrating and peripheral blood $\mathrm{T}$ lymphocytes from patients with chronic hepatitis of different etiology. Liver 1994; 14:161-166.

2 Martinez OM, Villanueva JC, Gershwin ME, et al. Cytokine patterns and cytotoxic mediators in primary biliary cirrhosis. Hepatology 1995;21:113-119.

3 Tsai SL, Lai MY, Chen DS. Analysis of rearranged T cell receptor (TCR) $\mathrm{V}$ beta transcripts in livers of primary biliary cirrhosis: preferential V beta usage suggests antigen-driven selection. Clin Exp Immunol 1996;103: 99-104.

4 Shindo M, Mullin GE, Braun-Elwert L, et al. Cytokine mRNA expression in the liver of patients with primary biliary cirrhosis (PBC) and chronic hepatitis B (CHB). Clin Exp Immunol 1996;105:254-259.

5 Harada K, Van de Water J, Leung PS, et al. In situ nucleic acid hybridization of cytokines in primary biliary cirrhosis: predominance of the Th1 subset. Hepatology 1997;25:791-796.

6 Nagano T, Yamamoto K, Matsumoto S, et al. Cytokine profile in the liver of primary biliary cirrhosis. J Clin Immunol 1999;19:422-427.

7 Shackel NA, McGuinness PH, Abbott CA, et al. Identification of novel molecules and pathogenic pathways in primary biliary cirrhosis: cDNA array analysis of intrahepatic differential gene expression. Gut 2001;49:565-576.

8 Shimoda S, Nakamura M, Ishibashi H, et al. HLA DRB4 0101-restricted immunodominant T cell autoepitope of pyruvate dehydrogenase complex in primary biliary cirrhosis: evidence of molecular mimicry in human autoimmune diseases. J Exp Med 1995;181:1835-1845.

9 Shimoda S, Nakamura M, Shigematsu $\mathrm{H}$, et al. Mimicry peptides of human PDC-E2 163-176 peptide, the immunodominant T-cell epitope of primary biliary cirrhosis. Hepatology 2000;31:1212-1216.

10 Burroughs AK, Rosenstein IJ, Epstein O, et al. Bacteriuria and primary biliary cirrhosis. Gut 1984;25: 133-137.

11 Butler P, Valle F, Hamilton-Miller JM, et al. M2 mitochondrial antibodies and urinary rough mutant bacteria in patients with primary biliary cirrhosis and in patients with recurrent bacteriuria. J Hepatol 1993; 17:408-414.

12 Harada K, Tsuneyama K, Sudo Y, et al. Molecular identification of bacterial $16 \mathrm{~S}$ ribosomal RNA gene in liver tissue of primary biliary cirrhosis: is Propionibacterium acnes involved in granuloma formation? Hepatology 2001;33:530-536.

$13 \mathrm{Xu}$ L, Sakalian M, Shen Z, et al. Cloning the human betaretrovirus proviral genome from patients with primary biliary cirrhosis. Hepatology 2004;39:151-156.

14 Akira S, Takeda K. Toll-like receptor signalling. Nat Rev Immunol 2004;4:499-511.

15 Beutler B, Rietschel ET. Innate immune sensing and its roots: the story of endotoxin. Nat Rev Immunol 2003;3:169-176.

16 Cella M, Jarrossay D, Facchetti F, et al. Plasmacytoid monocytes migrate to inflamed lymph nodes and produce large amounts of type I interferon. Nat Med 1999;5:919-923.

17 Kadowaki N, Antonenko S, Lau JY, et al. Natural interferon alpha/beta-producing cells link innate and adaptive immunity. J Exp Med 2000;192:219-226.

18 Luft T, Pang KC, Thomas E, et al. Type I IFNs enhance the terminal differentiation of dendritic cells. J Immunol 1998;161:1947-1953.

19 Lovgren T, Eloranta ML, Bave U, et al. Induction of interferon-alpha production in plasmacytoid dendritic cells by immune complexes containing nucleic acid released by necrotic or late apoptotic cells and lupus IgG. Arthritis Rheum 2004;50:1861-1872.

20 Jego G, Palucka AK, Blanck JP, et al. Plasmacytoid dendritic cells induce plasma cell differentiation through type I interferon and interleukin 6. Immunity 2003;19:225-234.

21 Tough DF, Borrow P, Sprent J. Induction of bystander $\mathrm{T}$ cell proliferation by viruses and type I interferon in vivo. Science 1996;272:1947-1950.

22 Farkas L, Beiske K, Lund-Johansen F, et al. Plasmacytoid dendritic cells (natural interferon-alpha/betaproducing cells) accumulate in cutaneous lupus erythematosus lesions. Am J Pathol 2001;159:237-243.

23 Ronnblom L, Alm GV. A pivotal role for the natural interferon alpha-producing cells (plasmacytoid dendritic cells) in the pathogenesis of lupus. J Exp Med 2001;194:F59-F63.

24 Ronnblom L, Eloranta ML, Alm GV. Role of natural interferon-alpha producing cells (plasmacytoid dendritic cells) in autoimmunity. Autoimmunity 2003;36: 463-472. 
25 Neuberger J. Primary biliary cirrhosis. Lancet 1997; 350:875-879.

26 Toda G, Zeniya M, Watanabe F, et al. Present status of autoimmune hepatitis in Japan-correlating the characteristics with international criteria in an area with a high rate of HCV infection. Japanese National Study Group of Autoimmune Hepatitis. J Hepatol 1997;26: 1207-1212.

27 Alvarez F, Berg PA, Bianchi FB, et al. International Autoimmune Hepatitis Group Report: review of criteria for diagnosis of autoimmune hepatitis. J Hepatol 1999;31:929-938.

28 Scheuer P. Primary biliary cirrhosis. Proc R Soc Med 1967;60:1257-1260.

29 Kroemer G, Hirsch F, Gonzalez-Garcia A, et al. Differential involvement of Th1 and Th2 cytokines in autoimmune diseases. Autoimmunity 1996;24:25-33.

30 Mosmann TR, Sad S. The expanding universe of T-cell subsets: Th1, Th2 and more. Immunol Today 1996; 17:138-146.

31 Berg PA, Klein R, Rocken M. Cytokines in primary biliary cirrhosis. Semin Liver Dis 1997;17:115-123.

32 Napoli J, Bishop GA, McCaughan GW. Increased intrahepatic messenger RNA expression of interleukins 2, 6, and 8 in human cirrhosis. Gastroenterology 1994;107:789-798.

33 Muller U, Steinhoff U, Reis LF, et al. Functional role of type I and type II interferons in antiviral defense. Science 1994;264:1918-1921.

34 Taniguchi T, Ogasawara K, Takaoka A, et al. IRF family of transcription factors as regulators of host defense. Annu Rev Immunol 2001;19:623-655.

35 Doyle S, Vaidya S, O'Connell R, et al. IRF3 mediates a TLR3/TLR4-specific antiviral gene program. Immunity 2002;17:251-263.

36 Doyle SE, O’Connell R, Vaidya SA, et al. Tolllike receptor 3 mediates a more potent antiviral response than Toll-like receptor 4. J Immunol 2003; 170:3565-3571.

37 Punturieri A, Alviani RS, Polak T, et al. Specific engagement of TLR4 or TLR3 does not lead to IFNbeta-mediated innate signal amplification and STAT1 phosphorylation in resident murine alveolar macrophages. J Immunol 2004;173:1033-1042.

38 Miettinen M, Sareneva T, Julkunen I, et al. IFNs activate toll-like receptor gene expression in viral infections. Genes Immun 2001;2:349-355.

39 Heinz S, Haehnel V, Karaghiosoff M, et al. Speciesspecific regulation of Toll-like receptor 3 genes in men and mice. J Biol Chem 2003;278:21502-21509.

40 Tanabe $\mathrm{M}$, Kurita-Taniguchi $\mathrm{M}$, Takeuchi K, et al. Mechanism of up-regulation of human Toll-like recep- tor 3 secondary to infection of measles virus-attenuated strains. Biochem Biophys Res Commun 2003; 311:39-48.

41 Sutherland CG, al-Badri AM, Howatson AG, et al. Immunolocalization of alpha interferon in liver disease. J Clin Pathol 1989;42:1065-1069.

42 Khan NU, Gibson A, Foulis AK. The distribution of immunoreactive interferon-alpha in formalin-fixed paraffin-embedded normal human foetal and infant tissues. Immunology 1990;71:230-235.

43 Khan NU, Pulford KA, Farquharson MA, et al. The distribution of immunoreactive interferon-alpha in normal human tissues. Immunology 1989;66: 201-206.

44 Nouri-Aria KT, Arnold J, Davison F, et al. Hepatic interferon-alpha gene transcripts and products in liver specimens from acute and chronic hepatitis B virus infection. Hepatology 1991;13:1029-1034.

45 Dienes HP, Hess G, Woorsdorfer M, et al. Ultrastructural localization of interferon-producing cells in the livers of patients with chronic hepatitis B. Hepatology 1991;13:321-326.

46 Fang JW, Wu PC, Lai CL, et al. Hepatic expression of interferon-alpha in chronic hepatitis B virus infection. Digest Dis Sci 1994;39:2014-2021.

47 Mihm S, Frese M, Meier V, et al. Interferon type I gene expression in chronic hepatitis C. Lab Invest 2004; 84:1148-1159.

48 Keskinen P, Nyqvist M, Sareneva T, et al. Impaired antiviral response in human hepatoma cells. Virology 1999;263:364-375.

49 Kerkmann M, Rothenfusser S, Hornung V, et al. Activation with CpG-A and CpG-B oligonucleotides reveals two distinct regulatory pathways of type I IFN synthesis in human plasmacytoid dendritic cells. J Immunol 2003;170:4465-4474.

50 Hemmi H, Kaisho T, Takeda K, et al. The roles of Tolllike receptor 9, MyD88, and DNA-dependent protein kinase catalytic subunit in the effects of two distinct CpG DNAs on dendritic cell subsets. J Immunol 2003;170:3059-3064.

51 Riordan SM, Skinner N, Nagree A, et al. Peripheral blood mononuclear cell expression of toll-like receptors and relation to cytokine levels in cirrhosis. Hepatology 2003;37:1154-1164.

52 Paik YH, Schwabe RF, Bataller R, et al. Toll-like receptor 4 mediates inflammatory signaling by bacterial lipopolysaccharide in human hepatic stellate cells. Hepatology 2003;37:1043-1055.

53 Kariko $\mathrm{K}$, Ni $\mathrm{H}$, Capodici J, et al. mRNA is an endogenous ligand for Toll-like receptor 3. J Biol Chem 2004;279:12542-12550 (Epub 12004 Jan 12516). 